\title{
Research in Construction - Lab to Land
}

\author{
Zacharia George \\ Principal Structural Consultant - PNP, Chennai
}

\begin{abstract}
Construction sector is a down to earth activity. Any industrial research in this sector should end up as results applicable in field are it in design or construction. Author describes a number of products / processes he developed as Researcher at CSIR-SERC and applied extensively in India at projects of technology transfer, from SERC and later in his career as Consultant in the Industry. These were to increase productivity, improve quality and to optimize use of critical materials as also to save construction time.
\end{abstract}

Keywords - Funicular Shells; Brick Shells; Lift Slab; Filler Slabs; Concrete Reinforcing Bars; 3 D Steel Structures; Space Frames; Braced Domes; Hyperbolied Shells; Large Panel Prefabrication; Reinforced Earth Design of RCC Elements.

\section{Introduction}

In the early sixties and seventies of Indian construction sector emphasis was on saving critical materials like steel and cement, as they were in short supply. Imports of technology were also to be restricted as foreign exchange reserves were meagre. This paper discusses about the development stages of construction field.

\section{Materials \& Methods}

\subsection{Funicular Shells}

There were two versions of this. One small - about 1 $\mathrm{m} \times 1 \mathrm{~m}$ - precast units $25 \mathrm{~mm}$ thick deriving its strength from the funicular profile in pure compression with no reinforcement, but bound by a small reinforced edge beam. The other was to construct these shapes over large spans, on form work with minimal ribs or without ribs even in brick masonry $100-125$ thick. For their use in industry such a proposal to be accepted by the conventional construction people who look to solid previous experience was difficult task, even when laboratory full scale tests are demonstrated. Two major applications came about after strange demonstrations demanded by the clients.

- For a major housing project for the army at Ambala, to build 1500 house for all ranks. The engineer colonel demanded that he will accept it if his 3 tonne truck can safely pass over these shell units. The test was successful and the process was adopted for the entire project in early sixties.

- A long temple corridor was to be built at Tiruchendur, Tamilnadu. The famous film producer Mr. Thevar was the sponsor of the project. He had to be convinced of the product by making his small elephant to stand on 4 legs on a single shell unit. This was also passed and the process adopted. Since then it has been extensively used on several projects across India and a BIS code was also made out. Applications at Chennai,
Hyderabad, Ahmedabad and in Kerala State Nirmithi Centers stand out ( Fig.1 \& 2).

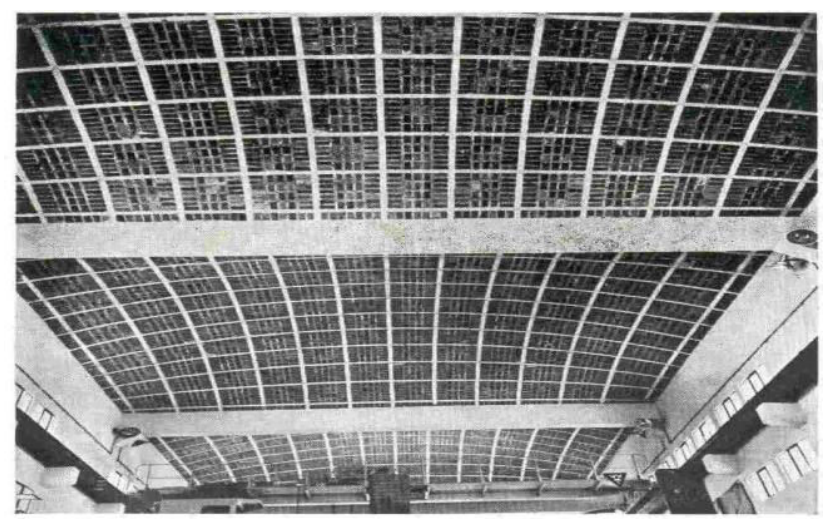

Fig.1: Funicular Shells

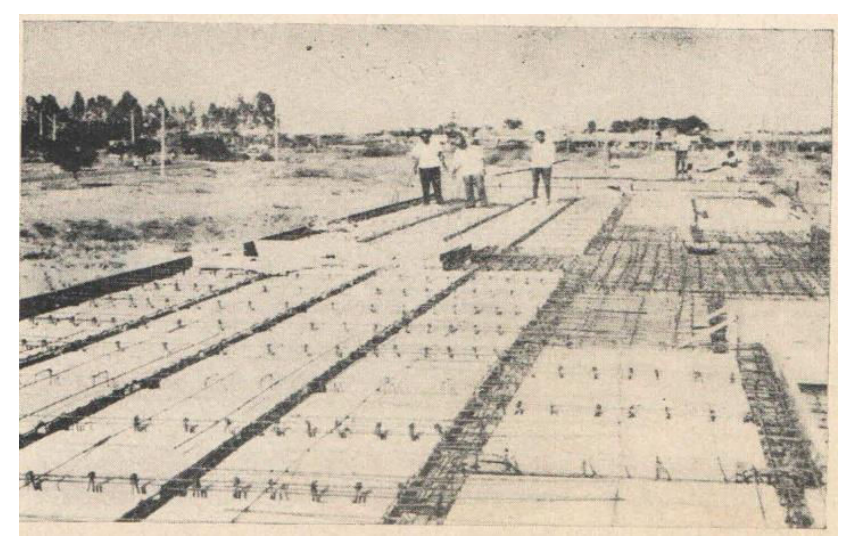

Fig.2: Funicular Shells

\subsection{Lift Slab (PT Slabs)}

Prestressed concrete has been used extensively in India for bridges, long span industrial buildings and for railway sleepers. Prestressing in slabs was introduced in India very late as PT slabs of spans 6 to $9 \mathrm{~m}$. However, the first prestressed slab as lift slab was demonstrated by SERC as 
early as 1960 's as part of R \& D at Roorkee by the authors team (Fig.3,4).

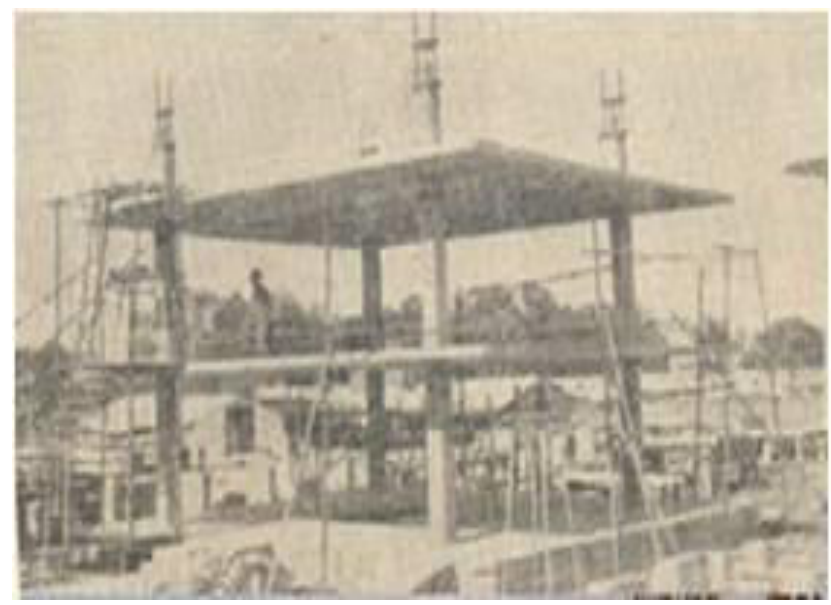

Fig.3: Lift Slab

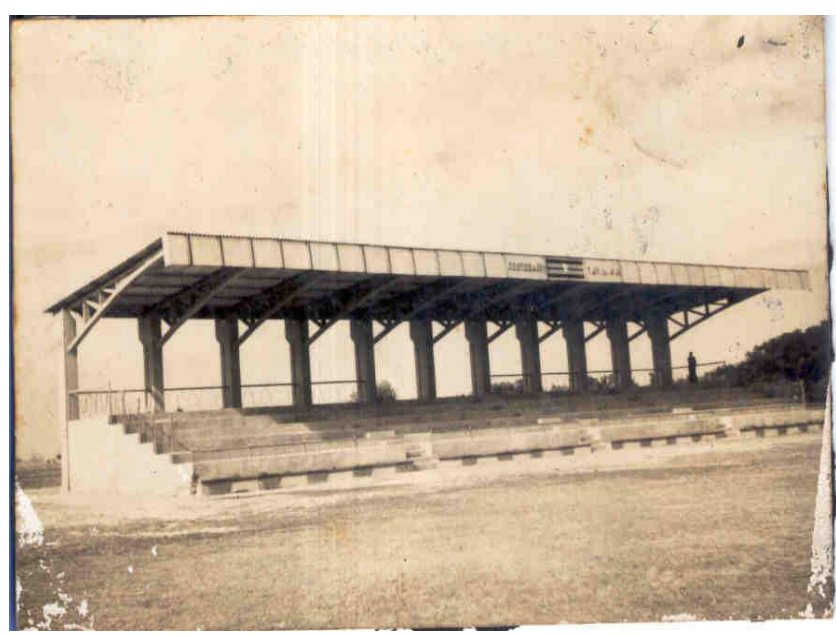

Fig.4: PSC Cantilever Truss

\subsection{Filler Slabs}

Concrete slabs of spans greater than $4,5 \mathrm{~m}$ will demand thicknesses above $140 \mathrm{~mm}$. It is well known to designers that $60 \%$ of concrete in slab is in tension zone and does not contribute to strength. A better option will be to use a lighter or cheaper material to replace this underused structural concrete. One such option is to use hollow clay blocks, or light weight cellular concrete blocks in such cases as has been done by the author at several Projects.

\subsection{Reinforcing Bars}

A good percentage of cost of concrete construction is for the reinforcing bars used in concrete (often 25 to $50 \%$ of cost of RCC). In the sixties, only MS bars of smooth surface with yield strength of $26 \mathrm{~N} / \mathrm{mm} 2$ was used in India. $\mathrm{R} \& \mathrm{D}$ at SERC by the authors' team developed bars of higher strength and increased bond strength by cold working of the bars, essentially by twisting. This was a 2 stage operation having to handle each bar for twisting. But in India of sixties could not afford to import alloying materials or twisting process / machines.

The bars developed and patented by the authors' team was liscenced to Tata Steel and several million tonnes of this steel was produced as Grip bars (TISCON) and used in India. As an import substitution work this received GOI inventions award. As the economy progressed and imports liberalized, higher grades of steel were produced and reinforcing bars of single operation (TMT) were made out of it. Today these bars of grade 500 and above are universally used in India. (Fig 5 - cold twisted / TMT bars).

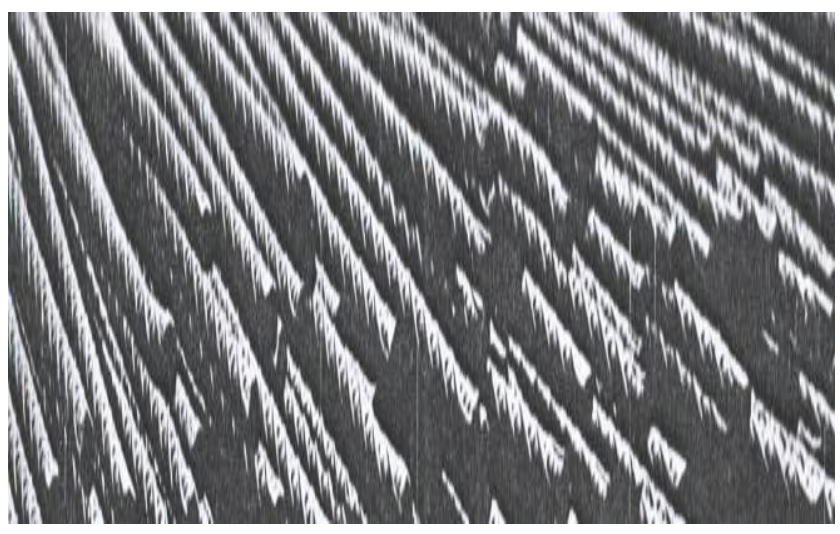

Fig.5: Reinforcement - TISCON BARS

\subsection{Space Frames / 3D Structures}

Covering large column free areas for assembly, sports and some industrial activities and hangars or Airport structures is a major problem in construction sector. Its design, manufacture and erection are equally difficult. The author had attempted to do this on a number of projects. His R \& D has also resulted in a patented process of braced domes (Fig 6,7).

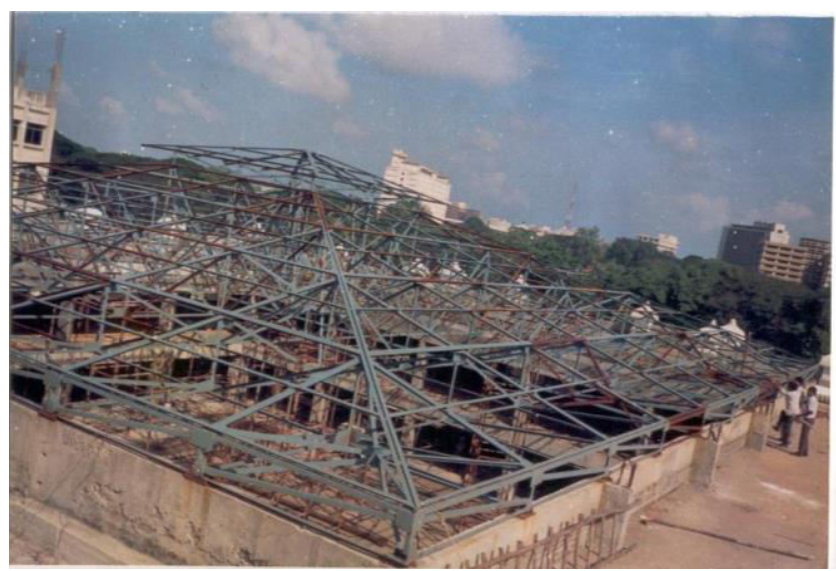

Fig.6: Steel Structures 


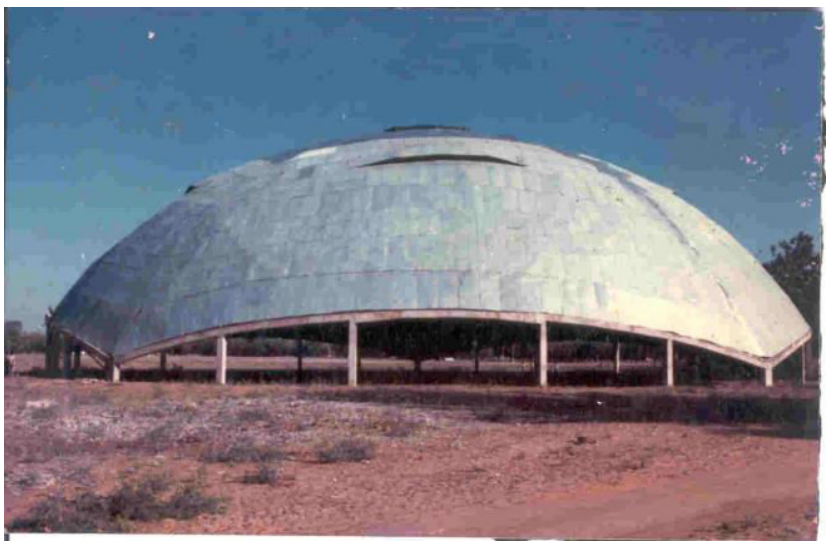

Fig.7: Steel Structures - Braised Dome

\subsection{HP Shells}

Precast thin concrete shells of $6-8 \mathrm{~mm}$ thickness, in plain RCC or by pretension concrete have been developed. These were used on a number of projects designed by the author. Precast elements of $2-2.50 \mathrm{~m}$ width in hyper boloid geometry can be formed of straight lines, shaped as a doubly curved surface. These are ideal for use for large spans. Notable applications are on the CSIR campus. (Air India, Chennai Airport, NIOT labs at Chennai and Tirupathi Q Complex (Fig. 8, 9)).

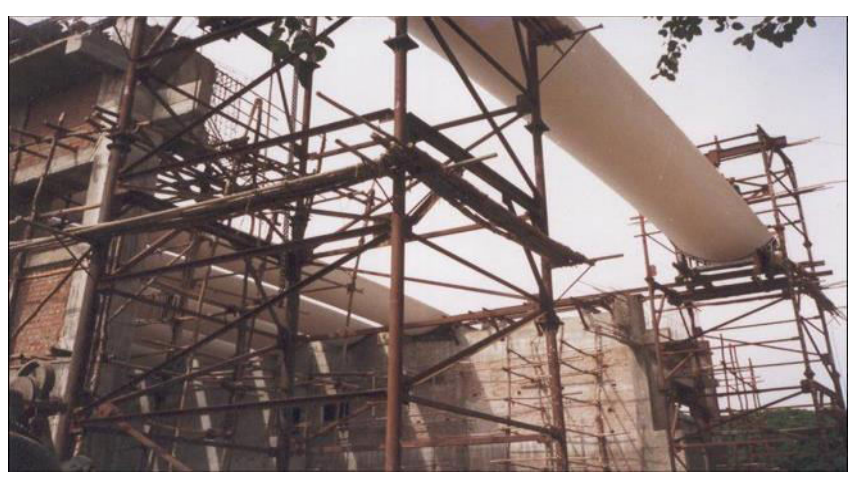

Fig.8: Pre Cast Hyperboloid Shells

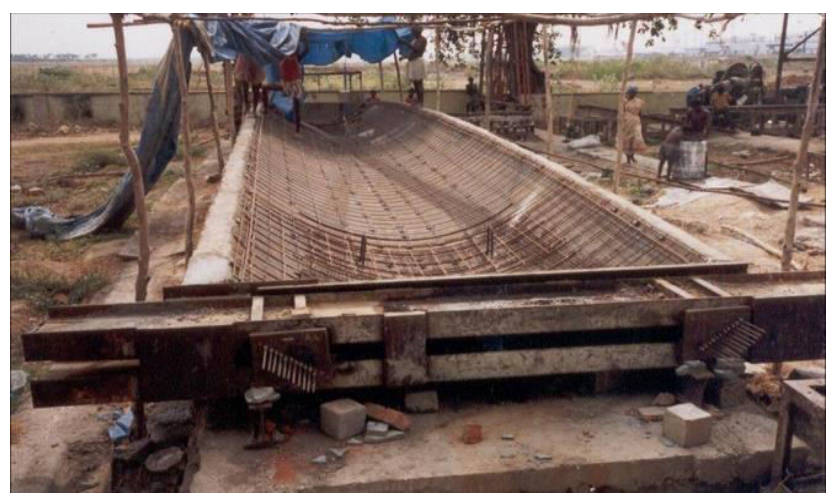

Fig.9: Pre Cast Hyperboloid Shells

\subsection{Large Panel Prefabrication}

Post War Europe adopted this technology for large scale construction for housing. Here concrete bonded room size panels are prefabricated in factories, brought to site and erected using tall tower cranes. India did not adopt this widely as we had no big highways, no tower cranes till the late eighties. However, attempts were made in Mumbai and Delhi to adopt these but with limited success. The author as part of his R \& D work at CSIR did a pilot project of constructing 144 medium flats $(<100 \mathrm{~m} 2)$ in four storeyed configurations. The walls were made of concrete bonded hollow clay blocks and slabs were made of waffle shaped shells all fabricated on on-site casting. A tower crane available with CSIR - SERC was used on the Tamilnadu Housing Board Project at Chennai (Fig 10). Like in other parts of India this technique also did not find favour with builders.

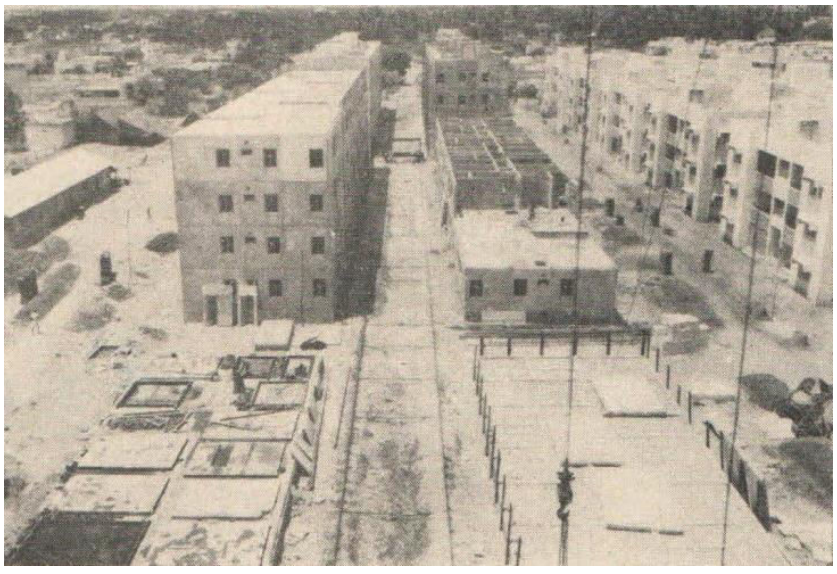

Fig.10: Large Panel Prefab (TNHB Chennai)

\subsection{Retaining Walls}

Traditionally to retain earth along the roads or plots in sloping terrains, the mass of the retaining wall is considered as the resisting force. Hence, roughly a retaining wall should have a base width of 0.4 to 0.50 of the height of earth retained. This is because the retained earth and the mass of retaining wall are considered as to separate elements.

Modern designs now try to integrate this by combining the two masses and reducing the wall to minimum thickness. This combination is possible by anchoring the thin facial wall into the soil by anchorages. The mass at the back should be of cohesive soil. The author has adopted this technique on a number of projects (Fig.11). The reinforced earth concept can now be seen on all the high way projects of elevated passages. On stable soil like laterite the walls may stand by itself but a grid can stablise it from falling down. 


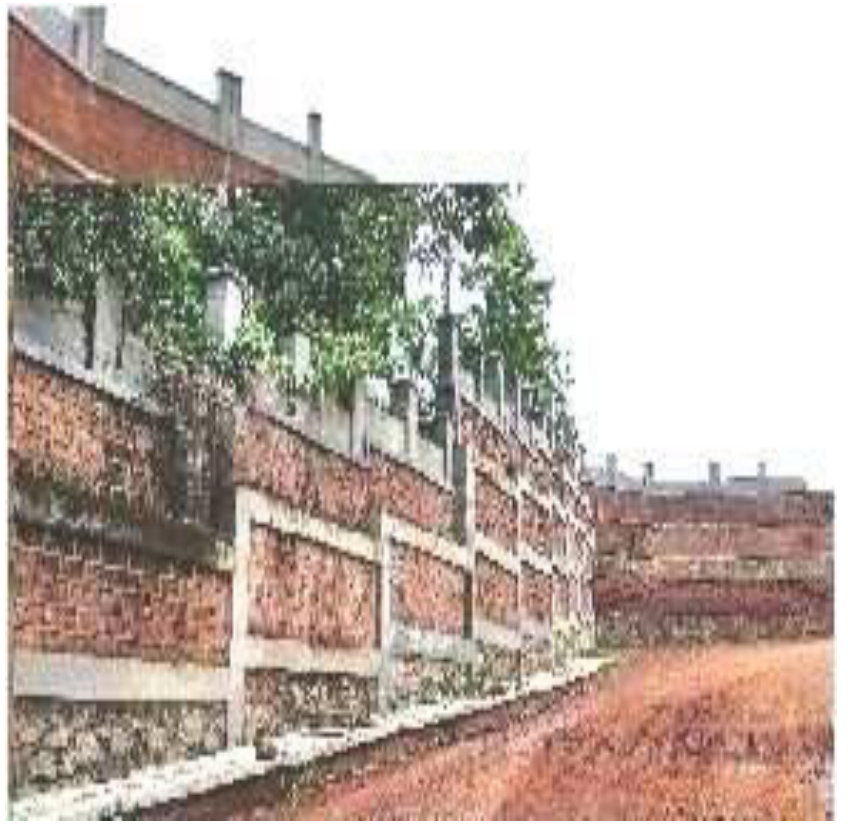

Fig.11: Reinforced Earth Retaining Wall

\subsection{Design of RCC Elements}

A lot of time is spent by designers for design of various RCC elements for buildings. Most Civil Engineers in construction go by what is given by the designer. It is necessary to check at least on a first cycle basis the designs they have received. A few design tables are presented here for reference.

- Slabs for given span / moments.

- Beams for given loadings / spans

- Columns for given Pu / Mu.

Computer aided designs are available for the design office. Yet the sites may not have the skills and infrastructure to verify this (Refer tables).
Table 1 : (Mu) Slab Moments - Interior Panels $\mathrm{kNm}$ at $10 \mathrm{kN} / \mathrm{m}^{2}$ Factored $1.5 \times 1.15$

\begin{tabular}{|c|c|c|c|c|c|}
\hline Panel Size & $\begin{array}{c}\text { Slab } \\
\text { Thickness } \\
\text { Mx / } \\
\text { WCx }^{2} \mathbf{x} \\
\text { Coeff }\end{array}$ & .045 & .034 & .032 & .024 \\
\hline $\begin{array}{r}4 \mathrm{mx} 5 \mathrm{~m} \\
276 \mathrm{X}\end{array}$ & $140 \mathrm{~mm}$ & $\begin{array}{c}12.42 \\
+A^{\prime}\end{array}$ & $\begin{array}{l}9.38 \\
\text { (A) }\end{array}$ & $\begin{array}{c}8.83 \\
\mathrm{~A}\end{array}$ & $\begin{array}{c}6.62 \\
\text { A }\end{array}$ \\
\hline & & .065 & .049 & .032 & .024 \\
\hline $\begin{array}{r}3.5 \mathrm{mx} 7 \mathrm{~m} \\
212 \mathrm{X} \\
\end{array}$ & $125 \mathrm{~mm}$ & $\begin{array}{c}13.78 \\
+\mathrm{C} \\
\end{array}$ & $\begin{array}{c}10.39 \\
(\mathrm{C})\end{array}$ & $\begin{array}{c}6.78 \\
\mathrm{~A}\end{array}$ & $\begin{array}{c}5.09 \\
\mathrm{~A}\end{array}$ \\
\hline & & .032 & .024 & .032 & .024 \\
\hline $\begin{array}{r}6 \mathrm{~m} \times 6 \mathrm{~m} \\
360 \mathrm{x} \\
\end{array}$ & $175 \mathrm{~mm}$ & $\begin{array}{l}19.87 \\
+C^{\prime}\end{array}$ & $\begin{array}{c}14.90 \\
\text { (C) }\end{array}$ & $\begin{array}{l}19.87 \\
+C^{\prime}\end{array}$ & $\begin{array}{l}14.90 \\
\text { (C) }\end{array}$ \\
\hline
\end{tabular}

\begin{tabular}{|l|c|c|c|c|c|c|}
\hline $\begin{array}{l}\text { Thic } \\
\text { kness }\end{array}$ & \multicolumn{7}{|c|}{$\rightarrow$ Bar Spacing } \\
\hline & Y8@ & Y8@ & Y8@ & Y10@ & Y10@ & Y10 @ \\
& 275 & 175 & 150 & 200 & 175 & 150 \\
& 2.22 & 2.85 & 3.33 & 3.93 & 4.49 & 5.23 \\
\hline 125 & 9.49 & 12.18 & 14.24 & 16.80 & 19.19 & - \\
\hline 140 & 11.99 & 15.39 & 17.99 & 21.22 & 24.24 & 28.24 \\
\hline 175 & 13.99 & 17.95 & 20.99 & 24.76 & 28.28 & 36.61 \\
\hline
\end{tabular}

Table 2: Resisting Moments

\begin{tabular}{|c|c|c|c|c|c|}
\hline \multirow[t]{2}{*}{ Ast. $\mathrm{cm}^{2}$} & \multicolumn{5}{|c|}{$\begin{array}{c}\text { Resisting Moments Mu CAPACITY OF BEAMS } \\
-(\mathrm{kN}-\mathrm{m}) \\
\text { DEPTH OF BEAMS }\end{array}$} \\
\hline & 300 & 450 & 600 & 750 & 900 \\
\hline 2.24 & 20 & 33 & & & \\
\hline 4.08 & 37 & 60 & & & \\
\hline 6.12 & 57 & 90 & 118 & 150 & 190 \\
\hline 7.22 & 61 & 106 & 140 & 178 & 226 \\
\hline 9.42 & & 139 & 183 & 233 & 295 \\
\hline 11.17 & & 164 & 216 & 275 & 345 \\
\hline 12.94 & & 200 & 250 & 319 & 400 \\
\hline 14.67 & & 226 & 286 & 365 & 460 \\
\hline 19.56 & & & 381 & 486 & 615 \\
\hline 24.09 & & & 469 & 598 & 755 \\
\hline 29.34 & & & & 728 & 920 \\
\hline $\begin{array}{l}\text { Arrive at } \\
\text { Design } \\
\text { Moments } \\
(\mathrm{Mu})\end{array}$ & & $\begin{array}{l}\text { Look for } \\
\text { nearest } \\
\text { RM for } \\
\text { given d }\end{array}$ & & & \\
\hline
\end{tabular}

Table 3: Column Section (Area of Steel - 4\% Max)

\begin{tabular}{|c|c|c|c|c|c|c|c|c|c|c|}
\hline \multicolumn{2}{|c|}{$\begin{array}{c}\text { Concrete } \\
\text { M25 }\end{array}$} & \multicolumn{9}{|c|}{ COLUMN SECTION (AREA OF STEEL - 4\% MAX) } \\
\hline \multirow[b]{2}{*}{$\mathrm{Pu}$} & \multirow[b]{2}{*}{$\mathrm{Mu}$} & \multirow{2}{*}{$300 \times 300$} & \multirow{2}{*}{$230 \times 375$} & \multirow{2}{*}{$230 \times 450$} & $300 \times 450$ & $300 \times 600$ & $375 \times 375$ & $450 \times 450$ & $300 \times 750$ & $600 \times 600$ \\
\hline & & & & & & & & & & \\
\hline & & & & & & & & & & \\
\hline 500 & 30 & $8 \mathrm{~cm}^{2}$ & $8 \mathrm{~cm}^{2}$ & $9 \mathrm{~cm}^{2}$ & & & & & & \\
\hline & & & & & & & & & & \\
\hline 1000 & 60 & $18 \mathrm{~cm}^{2}$ & $16 \mathrm{~cm}^{2}$ & $11 \mathrm{~cm}^{2}$ & $11 \mathrm{~cm}^{2}$ & & $12 \mathrm{~cm}^{2}$ & & & \\
\hline
\end{tabular}




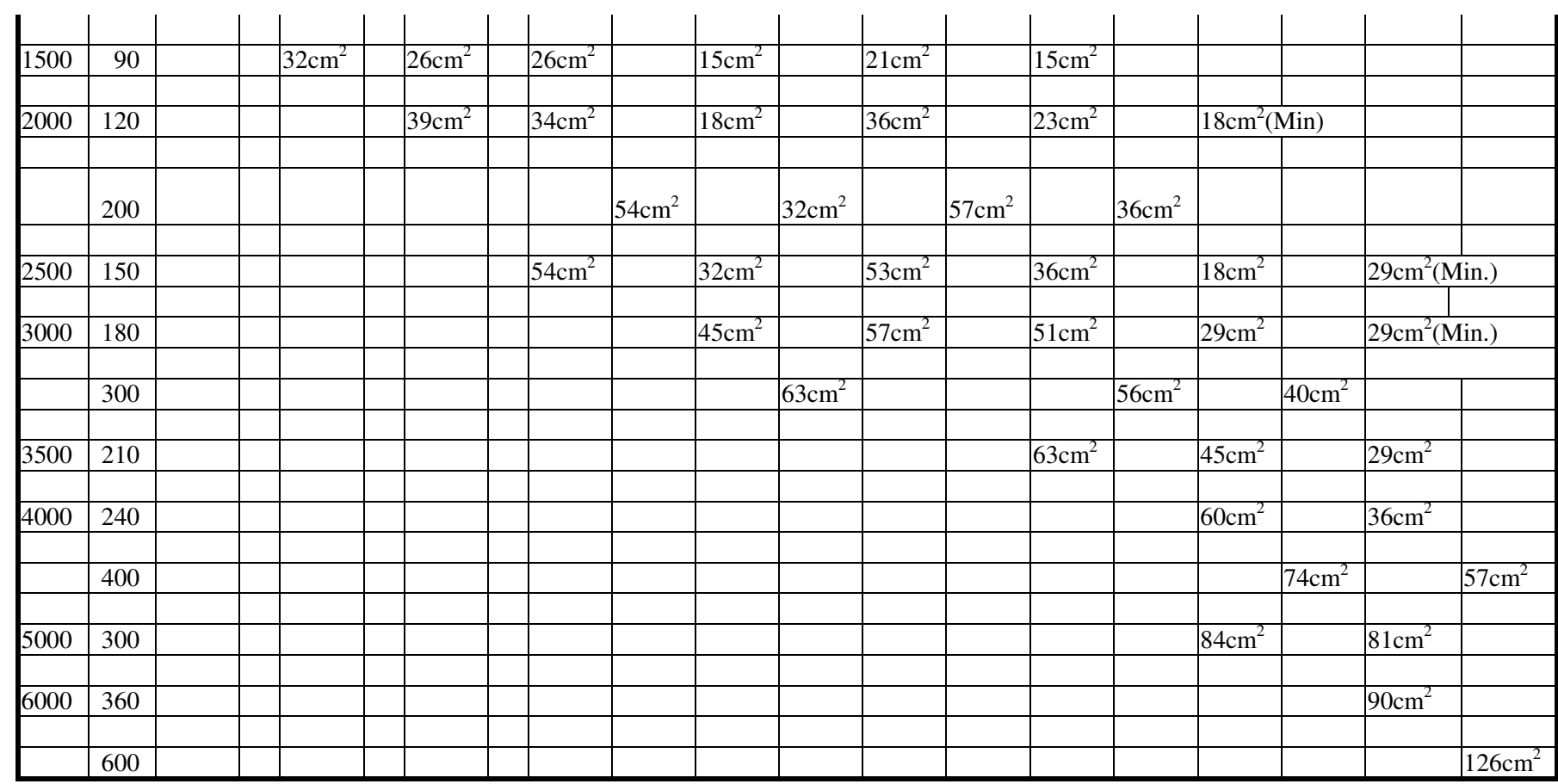

\section{Conclusion}

Today we have all these in plenty. R \& D in those days concentrated on these aspects. Some of these efforts and their results as application in industry are described here credits are due to Prof. Late G S Ramaswamy, Director SERC for guidance in these project to the author.

\section{Acknowledgement}

The Author acknowledges the co-operation extended by the used of the processes described above and for the photos of projects taken of their sites.

\section{References}

[1] Zacharia George, N. Sethuraman Waffle Shells - SERC Publications, 1975

[2] Zacharia George, K Mani, Brick Shells on Moveable Forms for Single Storey Buildings,Indian Concrete Journal 1978

[3] Zacharia George, K Mani , Large Panel Prefabrication, UNDP Workshop SERC, Chennai 1978.
[4] Zacharia George et al, Concrete reinforcement State of the Art Report , International Symposiums (SERC), Chennai 1982

[5] Zacharia George Structural Engineering in India, Journal of Structural Engineering Practices Vol 1 1982, USA

[6] Zacharia George , Cost Effective Construction Methods- FIP Bulletin, 1982

[7] Zacharia George, Cathedral Building At Varanasi, Indian Concrete Journal, 1990

[8] Zacharia George, et al Concrete Constructions Practices, including Formwork ICI -IWC 1993, Bangalore

[9] Zacharia George, Damages to Concrete and Repairs thereon CIPET Conference, Ahemdabad, 1995

[10] Zacharia George, Civil Engineering - Practical Approach IE(I) TNSC Seminar 2014

[11] Zacharia George, P.D Gupta, N. Balachander, IE(I) Annual Technical Volume - Architectural Engineering 2019

[12] Zacharia George, My 30 years of R\&D with CSIR, SERC and its Social Relevance, CPWA Annual Convention, Chennai 2020 